\title{
OS ENFRENTAMENTOS EM BUSCA PELA INTERDISCIPLINARIDADE ESCOLAR
}

\author{
GOMES, Vinicius ${ }^{1}$ \\ PUGGIAN, Cleonice ${ }^{2}$ \\ ALBUQUERQUE, Gabriela Girão de ${ }^{3}$
}

Recebido em: 2013-02-25

Aprovado em: 2013-04-19

ISSUE DOI: $10.3738 / 1982.2278 .870$

RESUMO: O presente artigo se propõe a fazer uma revisão da literatura, acerca do termo interdisciplinaridade, à luz de grandes estudiosos do tema e mostrar os principais obstáculos na busca pela interdisciplinaridade escolar. O termo interdisciplinaridade apresenta como núcleo central a expressão disciplina, logo a compreensão de interdisciplinaridade passa necessariamente pelo entendimento de disciplina. O princípio positivista se norteia na divisão do conhecimento em áreas específicas, a fim de promover uma profundidade maior em uma área mais restrita do conhecimento, assim o termo disciplina seja no campo epistemológico ou no campo pedagógico, representa uma imposição de limites de atuação, metodologias próprias, linguagens entre outros. Esses limites fragmentam o conhecimento e a realidade, o que dificulta uma visão mais global e totalitária da realidade. Na literatura o termo interdisciplinaridade não possui uma definição única, porém parece um consenso entre diversos autores como Morin, Fazenda, Pombo, Lenoir entre outros, que a interdisciplinaridade se apresenta como uma alternativa na fragmentação do conhecimento e os projetos interdisciplinares não passam pela extinção entre as disciplinas e sim pela busca da religação entre os saberes contidos em cada área do conhecimento, revitalizando as interrelações e interseções entre eles, seja através de uma atitude interdisciplinar, como defende Fazenda, ou no modo de pensar, como defende Morin.

Palavras Chave: Interdisciplinaridade. Fragmentação do conhecimento. Ensino.

\section{CLASHES IN SEARCH FOR SCHOOL INTERDISCIPLINARITY}

SUMMARY: This article aims to review the literature on the term interdisciplinarity, from the perspective of great researchers of the subject and show the main hurdles in the quest for interdisciplinarity school. The term interdisciplinarity comes from the expression discipline, then the understanding of interdisciplinarity is necessary to explain the discipline. The positivist principle is guiding the division of knowledge in specific areas in order to promote a greater depth in a more restricted area of knowledge, so the term discipline in the epistemological field or in the educational field, represents an imposition of limits of performance, methodologies own, languages, among others. These limits fragment knowledge and reality which makes a more global and totalitarian reality. In literature the term interdisciplinarity has no single definition, but it seems a consensus among many authors as Morin, Fazenda, Pombo, Lenoir among others, that interdisciplinarity is presented as an alternative in the fragmentation of knowledge and interdisciplinary projects do not pass between the extinction disciplines, but the search for reconnection between the knowledge contained in each knowledge area, revitalizing the intersections and interrelationships between them, either through an interdisciplinary approach as advocated by Fazenda or the way of thinking as advocated Morin.

Keywords: Interdisciplinarity. Knowledge fragmentation. Education

\footnotetext{
${ }^{1}$ Mestrando em Ensino de Ciências, Universidade do Grande Rio. Mestrado profissional em Ensino das Ciências na Educação Básica. Duque de Caxias-RJ, Brasil.pg.vinicius@yahoo.com.br

${ }^{2}$ Graduada em pedagogia e doutora em educação, Universidade do Grande Rio. Docente do Mestrado profissional em Ensino das Ciências na Educação Básica. Duque de Caxias-RJ, Brasil. cleo.puggian@gmail.com

${ }^{3}$ Graduada em Ciências Biológicas e doutora em Fisiopatologia Médica, Universidade do Grande Rio. Docente do Mestrado profissional em Ensino das Ciências na Educação Básica. Duque de Caxias-RJ,

Brasil. gabriela.albuquerque@unigranrio.br
} 


\title{
INTRODUÇÃO
}

A civilização nos apresenta a natureza e o entendimento do mundo com fatos e fenômenos desconexos e fragmentados, o que gera uma angústia e uma incompreensão da totalidade do assunto (FERREIRA, 2011).

A ciência foi dividida em nichos específicos na tentativa de se fazer estudos mais profundos a respeito de conteúdos mais restritos. O conhecimento fragmentado em diversas especializações, cada vez mais fechadas em si, dificultam o entedimento do todo.

A interdisciplinaridade surge nesse contexto como alternativa a fragmentação do conhecimento. Porém a definição de interdisciplinaridade não é clara e exata na literatura. Em uma análise etimológica da palavra interdisciplinaridade, Assumpção (2011), define que ela é formada por um prefixo inter- que fornece a idéia de interação, um sufixo latino -dade que confere o sentido de ação, qualidade, ou modo de ser e o núcleo da palavra -disciplina-. Logo se pressupõe a existência de ao menos duas disciplinas relacionadas em uma ação recíproca (LENOIR, 2001), ou seja, a interdisciplinaridade requer a aproximação entre disciplinas para que um ponto em comum possa ser trabalhado de forma conjunta .

Assim qualquer tentativa de entender a interdisciplinaridade deve passar por uma análise do entendimento do conceito disciplina, e posteriormente de interdisciplinaridade, nos campos espistemiológicos e pedagógicos, defendendo conceitos diversos e muitas vezes complementares.

Dessa forma, o presente artigo tem como objetivos realizar uma revisão da literatura, acerca do termo interdisciplinaridade, à luz de grandes estudiosos do tema e mostrar os principais obstáculos na busca pela interdisciplinaridade escolar.

\section{A DISCIPLINARIDADE}

As disciplinas podem ser entendidas como sistematizações ou organizações de conhecimentos científicos provenientes das ciências como a Matemática, a Física, a Química, a Biologia, a Geografia, a História, entre outras (PAVIANI, 2003). Essa especialização foi, na realidade, uma forma bastante lógica de se organizar conhecimentos para saber em que nível estamos e aonde precisamos chegar. Raynaut (2004, p.25), cita que:

\begin{abstract}
A novidade trazida pelo pensamento científico, quando comparado a outras formas de pensamento, foi justamente a de aceitar a dividir o mundo em facetas ou níveis de organização diferentes e tentar desenvolver instrumentos específicos - conceitos, definições de objetos, métodos de observação - para tentar explicar os fenômenos observados dentro dos limites assim delimitados. Foi esse reducionismo, esse esforço de abstração no próprio sentido da palavra, que possibilitou a produção de um conhecimento que permitisse uma ação mais decisiva sobre o mundo. Isso quer dizer que o recorte do real pelas disciplinas foi o movimento histórico do pensamento humano que viabilizou o surgimento e o desenvolvimento do pensamento científico.
\end{abstract}

É importante que se compreenda que esta divisão da ciência em áreas específicas não é algo improdutivo, ou desnecessário. "Não podemos recusar, nem menosprezar, nem esquecer que foi este procedimento analítico da ciência moderna que deu origem a todos conhecimentos e a todo o bem-estar que lhe devemos" (POMBO, 2005, p.6). O que deve ficar claro é que diversos conteúdos para que sejam trabalhados em sua totalidade necessitam de uma união dos conhecimentos advindos das diferentes áreas do saber. É aí que se consolida a proposta da interdisciplinaridade, onde o que se prega é uma cooperação entre as disciplinas e não a extinção destas. Segundo Morin (2002) é necessário uma interligação entre os diferentes saberes, reconstituindo a realidade, o todo, a fim de produzir novos conhecimentos e saberes. 
A disciplinaridade, assim como a interdisciplinaridade podem ser debatidas nos campos epistemológicos e pedagógicos, podendo apresentar finalidades, objetos, modalidades de aplicação e até mesmo diversidades de consequências, possibilitando a classificação da disciplinaridade em científica e escolar (LENOIR, 2001).

\subsection{DISCIPLINA NOS CAMPOS EPISTEMOLÓGICOS E PEDAGÓGICOS}

A palavra disciplina carrega um sentido intrínsico de limites, padrões, regras, liguagens e conceitos próprios a serem seguidos. No campo epistemológico, a disciplina pode ser entendida como uma ciência com um caráter de investigação, fazendo parte de um todo, sendo dividida em cada um dos ramos do conhecimento (LUCK, 1999).

Segundo Luck (1999), a disciplina, entendida como ciência apresenta um conjunto próprio de características e está baseada em um método fragmentador da realidade, permitindo um saber especializado e profundo.

A disciplina (ciência), entendida como um conjunto específico de conhecimento de caracterísitcas próprias, obtido por meio de método analítico, linear e atomizador da realidade, produz um conhecimento aprofundado e parcelar (as especializações). Ela corresponde, por tanto, a um saber especializado, ordenado e profundo que permite ao homem o conhecimento da realidade, a partir das especificidades, ao mesmo tempo que deixa de levar em consideração o todo de que faz parte (LUCK, 1999, p.37).

No enfoque epistemológico a disciplina está ligada à questão de produzir novos conhecimentos, ou seja, relacionada a pesquisa ou investigação de um determinado objeto de estudo. Assim, com o intuito de diferenciar a disciplina nos campos epistemológico e pedagógico, Lenoir (2001) utiliza o termo disciplina científica para se referenciar ao caráter de disciplina espistemológica e disciplina escolar para se referenciar a disciplina no campo pedagógico.

O enfoque pedagógico relaciona disciplina a uma atividade de ensino ou ensino de uma área da ciência respeitando uma ordem e uma organização de comportamento. Logo, a disciplina com enfoque pedagógico possui a finalidade no ensino, porém permanece a lógica fragmentadora da especialização, presente no enfoque epistemológico com o objetivo de facilitar o entendimento do conhecimento pelos estudantes (LUCK, 1999).

Para Leonir (2001) a disciplina com enfoque epistemológico, denominada de disciplina científica, e a disciplina com enfoque pedagógico denominada disciplina escolar, possuem lógicas e finalidades diferentes, ainda que apresentem alguma relação, pois defende que "mesmo se as matérias escolares formam certos empréstimos às disciplinas científicas, não constituem cópias de maneira alguma, tampouco resultam de uma simples transposição de saberes eruditos" (LEONIR, 2001, p.47).

Corroborando com essa relação entre os enfoques pedagógicos e epistemológicos da disciplina, Luck (1999, p.38) afirma que "no contexto pedagógico, o conhecimento já produzido, é submetido, novamente, ao tratamento metodológico analítico, linear e atomizador, agora com o objetivo de facilitar sua apreensão pelos estudantes."

A disciplina está vinculada ao paradigma positivista que se baseia no pressuposto de que o universo é composto de elementos que podem ser compreendidos de maneira separada e descontextualizada (JAPIASSU, 1976). Na construção disciplinar está intrínsica a fragmentação da realidade em unidades menores para a análise, cada ramo ou ciência é responsável pelo estudo de uma parcela da realidade, produzindo uma simplicação, uma vez que cada parcela se torna indepedente. A análise de cada parcela está caracterizada por um distanciamento do observador e o isolamento em relação ao contexto do qual o objeto

Nucleus, v.10, n.1, abr.2013 
pertencia (LUCK, 1999). Essa profunda fragmentação do conhecimento pode gerar certa insegurança no momento da aprendizagem de novos conteúdos, uma vez que cada disciplina do saber apresenta visões diferenciadas a respeito de um mesmo objeto de estudo. Nesse caso o estudante terá a difícil tarefa de, por conta própria, reunir mentalmente todas esses novas informações para que o todo possa ser compreendido.

\subsection{PROBLEMAS DA ESPECIALIZAÇÃO DO CONHECIMENTO}

As disciplinas científica e pedagógica, baseadas na construção de limites de atuação, possibilitaram a pesquisa e o ensino mais aprofundado de um objeto de estudo, permitindo uma exploração minuciosa de apenas uma parcela restrita da realidade, porém cabe uma reorganização desses conhecimentos, para o entendimento do todo. É inegável os avanços obtidos pela sociedade baseados no pensamento positivista, porém a especialização em apenas um pedaço da realidade não é o suficiente para entender situações complexas.

De acordo com Morin (2010), o conhecimento especializado e particulado em torno de um objeto de estudo pode resultar em uma abstração da realidade, uma vez que distancia o observador do objeto estudado, provocando uma "coisificação" do fenômeno, principalmente quando separado do contexto que esse objeto foi extraído. Assim a "coisificação do fenômeno" pode tornar o ensino menos significativo e pertinente aos alunos. Morin (2010), ainda cita que "a fronteira disciplinar, sua linguagem e seus conceitos próprios vão isolar a disciplina em relação às outras e em relação aos problemas que se sobrepõem às disciplinas" (p.106).

Logo, o processo de hiperespecialização dificulta o entendimento de assuntos complexos, como por exemplo, a condição humana que fica dividida em muitas áreas do saber, como as ciências biológicas, humanas, literatura e artes (MORIN, 2001), ou seja, a especialização não responde a problemas globais.

De acordo com Luck (1999), o paradigma positivista pressupõe que o todo possa ser recomposto com a soma das partes, logo as soluções dos problemas da realidade são possíveis mediante a intervenções setorizadas. No entanto, o que encontramos no cotidiano escolar é uma dificuldade enfrentada pelos alunos e pela escola na organização dos saberes desunidos e fragmentados em várias áreas do conhecimento. Nessa visão o aluno é entendido como um depósito de informações compartimentalizadas, em que os saberes aprendidos em uma disciplina pouco, ou em nada, se relacionam com os saberes de outras disciplinas.

Logo entender o complexo requer compreender o que foi tecido junto (MORIN, 2001), ou seja, está relacionado a uma interação entre elementos que só a análise de cada um separadamente não é o suficiente para se entender o todo. Como por exemplo, a questão ambiental passa por diferentes áreas do saber, mas não somente por uma soma dessas áreas, e sim pelas diferentes interações entre essas partes e a unidade. "O todo tem qualidades ou propriedades que não são encontradas nas partes, se estas estiverem isoladas umas das outras, certas qualidades ou propriedades das partes podem ser inibidas pelas restrições provenientes do todo" (MORIN, 2001, p.37).

Após décadas de especialização, fragmentação, compartimentalização e autoenclausuramento das ciências disciplinarizadas, a questão ambiental suscita um movimento reverso de des-especialização. A própria natureza e complexidade dos problemas a serem tratados no universo dos temas ambientais - sinergias, objetos mutantes, abrangências, interesses envolvidos, superposição de diferentes escalas, revisão de paradigmas consagrados etc - exige que as competências a serem mobilizadas sejam amplas (BURSZTYN, 2004, p.70).

Para Morin (2001) o paradigma positivista presente no conceito de disciplina está vinculado ao reducionismo e a simplificação dos objetos de estudo, não permitindo o entendimento do todo, uma vez que 
esse paradigma isola uma parcela da realidade do contexto que está inserida e torna dimensional o que muitas vezes é multimensional.

O princípio da redução leva a restrição do complexo ao simples, limitando a forma de pensar ampla em uma forma de pensar tecnicista em torno de um objeto, tornando o homem cego para os problemas globais, em vista do parcelamento e fragmentação desse problema. Durante o nosso processo educativo somos ensinados a fragmentar o conhecimento e não somos treinados na reorganização e integração desses conhecimentos, o que limita a nossa mente a globalizar e contextualizar. Morin (2001, p.43) cita que:

Como nossa educação nos ensinou a separar, compartimentalizar, isolar e, não a unir conhecimento, o conjunto deles constitui um quebra-cabeças ininteligível. As interações, as retroações, os contextos e as complexidades que se encontram na man's land entre as disciplinas se tornam invisíveis. Os grandes problemas humanos desaparecem em benefício dos problemas técnicos particulares. A incapacidade de organizar o saber disperso e compartimentado conduz à atrofia da disposição mental natural de contextualizar e de globalizar.

Assim se torna invisível o conhecimento que surge nas fronteiras entre as disciplinas, como é o caso da evolução do conhecimento molecular do DNA que nasceu entre os limites da biologia e da química e ainda com migrações de outras disciplinas como é o caso da idéia de código presente no gene, onde a noção de código é originado da linguagem jurídica e passou a ser integrante da linguagem da disciplina biológica (MORIN, 2010). Assim o conhecimento do DNA não surgiu limitado a uma disciplina e sim da religação dos conhecimentos presentes em diversas especializações.

Para interpretarmos fatos ou tomar decisões, utilizamos uma integração de informações provenientes de nossa educação ou de experiências vividas. Esse processo informal representa uma espécie de análise interdisciplinar. A análise interdisciplinar em um ambiente formal envolve a utilização de conhecimentos especializados bem como conceitos adquiridos em disciplinas específicas. A integração dessas peças é que irá criar um novo conhecimento ou compreensão mais profunda (SEIPEL, 2005). Genericamente, pode-se definir a experiência interdisciplinar como o confronto de diferentes saberes organizados ou disciplinares que desenham estratégias de pesquisa, diferentes daquelas que faria cada saber por seu lado e fora dessa interação (FLORIANI, 2004).

Permitindo a abertura da disciplina, mesmo que parcialmente, obtivemos o que Pombo (2005) denomina de conhecimentos de fronteira, onde novas disciplinas e conhecimentos surgem em zonas de interseção, como é o caso das ciências ecológicas, ambientais e ainda biofísica e bioquímica. Em uma análise superficial, podemos observar o surgimento de novos cursos universitários que se formam em Zonas de Fronteira, como o caso da Engenharia Ambiental, Ciências da Natureza, Engenharia Florestal.

Segundo Klein (2001, p.114):

Em 1990, o primeiro relatório nacional da força-tarefa de estudos interdisciplinares, em conjunto com o estudo das áreas de concentração na graduação, realizado pela Association of American Colleges (Associação Americana de Faculdades), destacou o papel de novos campos de conhecimento. A força-tarefa encontrou um vasto número de carreiras interdisciplinares, incluindo estudos de políticas públicas e internacionais, estudos trabalhistas e legais, ecologia humana, ecologia social, neurociência, bioquímica e biologia molecular, ciências ambientais e biologia marinha, ciência cognitiva e ciência da informação.

Fica claro que uma abertura da disciplina é necessária para ampliar o pensamento e o conhecimento de uma maneira mais contextualizada e totalitária, porém parece um consenso entre os autores (FAZENDA, 2007; MORIN, 2010; LENOIR, 2001; POMBO, 2005; KLEIN, 2001; LUCK, 1999) que essa abertura não 
passa pela exclusão por completo das disciplinas e sim por aprender a restrurar e religar as diferentes estruturas, a fim de recompor o todo.

\section{CONCEITOS DE INTERDISCIPLINARIDADE}

O termo interdisciplinaridade surgiu em um contexto de ansiedades acerca do declínio das diferentes formas de educação, sendo primeiramente utilizado nas ciências sociais em meados de 1920 e torna-se comum através das ciências sociais e humanas imediatamente após a segunda guerra mundial (MORAN, 2010).

Corroborando com Moran e Thiesen (2008) defende que o termo interdisciplinaridade ganhou força principalmente nos campos das ciências humanas e de educação, com intuito de superar a fragmentação do conhecimento e o caráter de especialização com raízes na tendência positivista e mecanicista.

A literatura especializada apresenta inúmeras concepções para o termo interdisciplinaridade, cada qual com algumas particularidades. Fazenda (2007), defende que não existe um consenso na definição de terminologia, porém geralmente se restringe a quatro conceitos básicos que configuram um nível quanto ao grau de integração: Multi ou pluri, inter e transdisciplinar. Fazenda (2007, p. 31) explica que:

A partir da análise de algumas contribuições ao conceito de interdisciplinaridade do ensino feitas por alguns peritos no assunto, como Boisot, Guy Michaud, Jantsch e Heckausen, concluí que existe atualmente uma preocupação em definir a terminologia adotada, embora ela se baseie em diferentes pressupostos. Posto que a terminologia adotada é bastante vasta, a tendência mais acentuada é restringir-se a quatro conceitos básicos: Pluri, multi, inter e trans-disciplinaridade; em geral, existe uma gradação desses conceitos, que se estabelece na esfera de coordenação entre as disciplinas.

Seguindo nesse raciocínio, a autora trabalha com a idéia de que a multi ou pluridisciplinaridade está apenas na justaposição de conteúdos de duas ou mais disciplinas com um envolvimento que não ultrapassa os

limites disciplinares, como por exemplo, a linguagem, ou seja, a multi ou pluridisciplinaridade seriam estágios para atingir a interdisciplinaridade. Já a interdisciplinaridade estaria relacionada a uma reciprocidade, em um regime de interação e co-propriedade, a uma atitude de substituição de uma fragmentação por um sentido de unidade do ser humano. Em último nível de integração, essa autora apresenta a transdisciplinaridade como uma utopia.

Pombo (2005), também defende que não existe uma explicação clara e exata para o que seja a interdisciplinaridade, no entanto, em um de seus textos, a autora faz o uso de uma série de palavras e expressões que se remetem à interdisciplinaridade de forma bastante interessante. Dentre elas estão: sensibilidade à complexidade, capacidade de procurar mecanismos comuns, atenção a estruturas profundas que possam articular o que aparentemente não é articulável, curiosidade, abertura de espírito, gosto pela colaboração, pela cooperação, pelo trabalho em comum.

Thiesen (2008) acredita que quando se trata de disciplina estamos impondo limites a um objeto de estudo ou conhecimento, seja através da linguagem, do campo de ação, na forma de pensamento. Como a interdisciplinaridade se propõe a uma expansão desses limites disciplinares, conceituar interdisciplinaridade requer impor limites, definir onde ela começa e onde pode chegar, assim estaríamos limitando a interdisciplinaridade a uma disciplina.

O consenso presente na literatura parece indicar que a interdisciplinaridade é uma alternativa ao saber fragmentado, uma superação dos limites impostos pelo positivismo presente nas ciências seja através do que Fazenda (2007) denomina como atitude ou no modo de pensar de Morin (2010). 


\subsection{OS OBSTÁCULOS E A BUSCA PELA INTERDISCIPLINARIDADE ESCOLAR}

A escola como local legítimo de aprendizagem, reconstrução e produção do conhecimento precisará acompanhar o ritmo das mudanças que ocorrem em todos os segmentos que compõem a sociedade, uma vez, que o mundo está cada vez mais interconectado e complexo (THIESEN, 2008).

O paradigma positivista que norteia o ensino e a aprendizagem na escola proporciona uma especialização, ou seja, estipula um estudo mais minucioso de apenas uma parte da realidade, o que fornece uma maior segurança na atuação do professor, diminuindo a chance de erro, tanto conceitual, quanto de linguagem e métodos de atuação na sala de aula.

Historicamente nota-se que os conhecimentos escolares vêm sendo trabalhados de forma fragmentada dentro de disciplinas de conteúdos específicos. A separação do conhecimento na disciplina escolar pode ocasionar uma redução do conhecimento e proporcionalmente na maneira de pensar, tornando o objeto de aprendizado sem contexto e com pouca significação para os alunos.

O ensino da reprodução humana na escola básica, por exemplo, fica diretamente vinculado a disciplina de Biologia, que devido aos seus limites de atuação acabam por enfatizar apenas os aspectos biológicos da reprodução, como a fecundação, os aparelhos reprodutores, métodos anticoncepcionais, doenças sexualmente transmissíveis. Porém todo esse conhecimento depende do entendimento de temas como o ato sexual, sexualidade, a vida e sua valorização. Para alcançar esses conhecimentos e depois religa-los é necessária uma abertura na disciplina biológica para a migração de conhecimentos provenientes de outras disciplinas, como a História, Sociologia e Literatura.

Outro exemplo é o ensino da ecologia que se sustenta como um tema geralmente abordado na Biologia, que permite a abertura da disciplina para o conhecimento de outras disciplinas. Segundo Morin (2010, p. 28):

A Ecologia, que tem um ecossistema como objeto de estudo, recorre a múltiplas disciplinas físicas para apreender o biótopo e às disciplinas biológicas (Zoologia, Botânica, Microbiologia) para estudar a biocenose. Além disso, precisa recorrer às ciências humanas para analisar as interações entre o mundo humano e a biosfera. Assim disciplinas extremamente distintas são associadas e orquestradas na ciência ecológica.

O estudo do meio ambiente traz necessariamente a exigência da interdisciplinaridade em função da complexidade do assunto. $\mathrm{O}$ meio ambiente inscreve-se dentro de uma representação ampla, que reúne subsistemas que interagem e mesmo compartilham elementos comuns, embora se organizem segundo propriedades estruturais e funcionais diferentes (RAYNAUT, 2004). Segundo Floriani (2004), a noção de meio ambiente tende a ser multicêntrica, complexa e objeto de diferentes escalas de abordagem, devendo constituir um dos eixos centrais nos processos de desenvolvimento das sociedades. Nesse contexto, verifica-se o crescente surgimento de programas de pós-graduação interdisciplinares em meio ambiente (Coordenação de Aperfeiçoamento de Pessoal de nível Superior) o que mostra a preocupação das instituições de ensino superior a respeito desta questão.

A partir da análise de documentos de Conferências Internacionais do Meio Ambiente e da legislação educacional brasileira, fica claro que entre professores e pesquisadores, é comum o entendimento de que a interdisciplinaridade é imprescindível para o êxito das práticas de educação ambiental (LIMA, 2006). Por outro lado, a resistência à interdisciplinaridade, tanto no âmbito do ensino, quanto da pesquisa, demonstra temor da perda do exclusivismo ou da autonomia das disciplinas (SILVA, 2011).

Assim as práticas interdisciplinares se tornam inevitáveis no cotidiano escolar, porém Fazenda (2011) defende que muitos professores não sabem ao certo, como utilizar essa abordagem no ensino. Ainda com a 
amplitude que as práticas e temas disciplinares podem alcançar, há uma insegurança por parte dos professores no domínio de todos os tópicos abordados e na autonomia em sala de aula. Além disso, muitos relatam falta de tempo para realizarem pesquisas que possam auxiliá-los em um trabalho interdisciplinar diferenciado (AUGUSTO et al, 2008; SANTOS et al, 2008; SILVA, 2011). No entanto, deve-se ficar que o contexto escolar se estrutura de forma a dificultar a prática da interdisciplinaridade, principalmente quando se fala do currículo escolar, elaborado de forma totalmente disciplinar, não dando margem muitas vezes à realização de atividades que possam priorizar a prática de estudos do conteúdo de forma mais integrada.

No entanto, existem balizas que podem ser utilizadas para permitir uma maior integração desses conteúdos. Segundo Auler (2007, p.7), a interdisciplinaridade "requer a análise sob vários olhares disciplinares articulados em torno de um tema constituído de um problema aberto, sendo os problemas ambientais representantes típicos". Ou seja, não apenas um professor precisa ser detentor de todo conhecimento escolar, mas um grupo de professores atuando em conjunto pode resolver a questão da integração dos conteúdos. "Supera-se, assim, uma compreensão de interdisciplinaridade, bastante problemática, que se limita a buscar interfaces entre as disciplinas constituintes dos currículos tradicionais das escolas" (AULER, 2007, p.7).

Diversos estudos tem mostrado a importância da integração de conteúdos no ambiente escolar. Um exemplo bem estudado é o caso da biologia e matemática, onde a unificação dos conteúdos promove o aumento de interesse dos alunos além de levar a uma melhor interpretação do assunto estudado, melhorando a aprendizagem (BIALEK et al, 2004; MADLUNG et al, 2011; ROBEVA et al, 2009).

A aproximação entre a biologia e a matemática na escola já se encontra presente em algumas disciplinas em que essa separação não é possível para o entendimento do tema. Como exemplo, podemos destacar a genética mendeliana onde os conceitos e leis de Mendel dependem intrinsicamente dos conceitos básicos de probabilidade presentes na matemática. $\mathrm{O}$ avanço dos estudos da genética mendeliana só é possível com o avanço nos estudos de probabilidade. Porém no ensino básico dificilmente encontramos um planejamento organizado entre professores de Biologia e Matemática para o ensino desse tema.

O processo de busca pela interdisciplinaridade parece inevitável na escola, uma vez que o processo de seleção de alunos para vagas públicas e particulares no ensino superior está relacionado à prova do ENEM (Exame Nacional do Ensino Médio). Nesse processo seletivo os alunos se deparam com uma prova dividida em áreas do conhecimento, como: Ciências Humanas e suas tecnologias, Ciências da Natureza e suas tecnologias, Matemática e suas tecnologias e por fim, Linguagens, códigos e suas tecnologias.

Logo podemos observar uma busca pela interdisciplinaridade nas provas do chamado novo ENEM, uma vez que encontramos questões que não se limitam a área de atuação de conhecimento e linguagem restritos apenas a uma disciplina. As questões, em sua maioria, ainda contam com textos que refletem a realidade da sociedade, buscando uma contextualização dos assuntos abordados, assim fornecendo significado a elas.

Porém esse processo, apesar de oferecer um rumo na busca pela interdisciplinaridade e a superação da fragmentação do ensino da realidade, ainda possui intimamente presente o paradigma positivista que circunda o ensino. No paradigma positivista a realidade está submetida a um limite de atuação seja no pensamento ou na linguagem. Assim quando estipulamos as áreas de conhecimento do ENEM, estamos ampliando os limites das disciplinas, porém ainda impomos limites a elas, tornando as áreas de conhecimento em novas disciplinas. Fica evidente que mesmo que o ENEM não alcance a interdisciplinaridade é um bom passo em sua busca.

Assim, como citado acima, um consenso na literatura da busca pela interdisciplinaridade não passa pela exclusão entre as disciplinas e sim por religação entre os saberes, em uma reconstrução do todo a partir das disciplinas. 
Luck (1999) defende que existe muita confusão no que seria chamado de interdisciplinaridade e ainda afirma que as práticas interdisciplinares não podem ser confundidas com trabalho cooperativo e em equipe; integração de funções; cultura geral; justaposição de conteúdos; adoção de um único método de trabalho por diferentes disciplinas.

Fazenda (2007) defende uma atitude disciplinar por parte dos professores, que os retire da acomodação de práticas e pensamentos positivista em caminho a um trabalho em parceria, integrador que supere os limites artificiais impostos pelo método atomizador disciplinar.

Atitude de quê? Atitude de busca de alternativas para conhecer mais e melhor; atitude de espera perante atos não-consumados; atitude de reciprocidade que impele à troca, ao diálogo com pares idênticos, com pares anônimos ou consigo mesmo; atitude de humanidade diante da limitação do próprio saber; atitude de perplexidade diante da limitação do próprio saber; atitude de perplexidade ante a possibilidade de desvendar novos saberes; atitude de desafio diante do novo, desafio de redimensionar o velho; atitude de envolvimento e comprometimento com os projetos e as pessoas neles implicadas, atitude, pois, de compromisso de construir sempre da melhor forma possível; atitude de responsabilidade, mas sobretudo de alegria, de revelação, de encontro, enfim, de vida (FAZENDA, 2007, p.14).

Nesse mesmo artigo, Fazenda (2007), defende que o menos importante é a classificação das práticas buscando a interdisciplinaridade, em multi, pluri, inter ou transdisciplinares. Isso pode ocasionar um desestímulo e o abandono da ação, e a busca pelas práticas interdisciplinares dependem de um processo contínuo, caracterizado por estágios, pela vivência, em uma sucessão que permite o entendimento dos professores envolvidos e uma transformação gradual da prática pedagógica.

Segundo Klein (2001) a integração é a chave para a interdisciplinaridade. Nos cursos multidisciplinares as perspectivas disciplinares são apresentadas em série, deixando a integração e síntese por conta dos alunos. Nos cursos "interdisciplinares" a integração e a síntese dos projetos são realizadas mutuamente, o que propicia um desenvolvimento mais amplo.

Klein ainda defende nesse mesmo artigo, que a integração na interdisciplinaridade depende de um equilíbrio entre amplitude, profundidade e síntese. A amplitude assegura uma larga base de conhecimento. A profundidade assegura o requisito disciplinar de conhecimento mais detalhado da tarefa a ser realizada. $\mathrm{E}$ a síntese requer o processo de integração, onde não se espera que os alunos consigam integrar o que os professores não possam fazer.

Na literatura é mais comum encontrarmos trabalhos em torno de um problema complexo, como o uso de drogas, AIDS e meio ambiente. Esses temas centrais norteiam a construção de um novo currículo, como exemplificado por Klein (2001), no processo educativo Norte Americano. Pombo (2005) corrobora defendendo que temas como a juventude urbana, o envelhecimento, a violência, o clima, a manipulação genética só podem ser debatidos e passíveis de respostas através de um enfoque interdisciplinar.

No cotidiano escolar, vídeos, músicas e textos podem auxiliar a trazer a realidade para a sala de aula em um debate mais amplo e totalitário. Por exemplo, a música "O que é, o que é" do compositor e cantor Gonzaguinha, permite uma discussão em torno do sentido da vida, permitindo enfoques biológicos, humanos e sociológicos intimamente relacionados, transitando na zona de interseção dos conhecimentos e ainda na fronteira dos conhecimentos disciplinares, como por exemplo, o debate sobre a valorização da vida.

\section{CONSIDERAÇÕES FINAIS}

Aprofundando os estudos na área da interdisciplinaridade podemos perceber que esta prática visa a 
Construção de conhecimentos que ultrapassem as fronteiras entre as disciplinas. A busca pela interdisciplinaridade acarreta uma sobrecarga de trabalho, romper hábitos e acomodações, compromisso, certo medo de errar, envolvimento, em buscar algo novo e desconhecido, ou seja, da incorporação de condutas e atitudes que promova a agregação dos saberes. Logo a realização de práticas interdisciplinares está submetida a situações que podem trazer erros recorrentes e inicialmente ficar bastante distante do que pode ser de fato considerado interdisciplinaridade.

Aos professores, cabe a tarefa de compreenderem o quão relevante pode ser essa integração de saberes e iniciarem uma atitude ou modo de pensar interdisciplinar que se associe ao empenho de mudanças na prática, tornando o trabalho educacional mais significativo e mais produtivo para os professores e, especialmente para os alunos.

\section{REFERÊNCIAS}

AUGUSTO, T. G. S.; CALDEIRA, A.M.A. A interdisciplinaridade na educação em ciências: professores de ensino médio em formação e em exercício. In: ARAUJO, E.S.N.N.; CALUZI, J.J.; CALDEIRA, A.M.A. (Org.). Práticas integradas para o ensino de biologia. São Paulo: Escrituras, 2008. p.189-203.

AULER, D. Enfoque ciência-tecnologia-sociedade: pressupostos para o contexto brasileiro. Ciência \& Ensino. v. 1, p. 1-20, 2007.

BIALEK, W.; BOTSTEIN, D. Introductory science and mathematics education for 21 st-century biologists. Science. v. 303, p.788-790, 2004.

BURSZTYN, M. Meio ambiente e interdisciplinaridade: desafios ao mundo Acadêmico. Desenvolvimento e Meio Ambiente. n. 10, p. 67-76, 2004.

FAZENDA, I. Interdisciplinaridade um projeto em parceria. 6.ed. São Paulo: Loyola, 2007.

FAZENDA, I. Interdisciplinaridade: definição, projeto, pesquisa. In: FAZENDA, I. C. A. (Org.) Práticas interdisciplinares na escola. São Paulo: Cortez, 2011. p.13 - 18.

FERREIRA, S. Introduzindo a noção de interdisciplinaridade. In: FAZENDA, I. C. A. (Org.) Práticas interdisciplinares na escola. São Paulo: Cortez, 2011. p.33-35.

FLORIANI, D. Disciplinaridade e construção interdisciplinar do saber ambiental. Desenvolvimento e Meio Ambiente. n. 10, p. 33-37, 2004.

JAPIASSU, Hilton. Interdisciplinaridade e patologia do saber. Rio de Janeiro: Imago, 1976.

KLEIN, J.T. Ensino interdisciplinar: didática e teoria. In: FAZENDA, I.C.A.(org.). Didática e interdisciplinaridade. 6 ed. Campinas: Papirus, 2001, p.109 - 132.

LENOIR, Y. Didática e interdisciplinaridade: uma complementaridade necessária e incontornável. In: FAZENDA, I.C.A.(org). Didática e interdisciplinaridade. Campinas: Papirus, 2001

LIMA, M. J. G. S. Reflexões sobre a prática interdisciplinar da educação ambiental no contexto escolar. In: REUNIÃO ANUAL DA ANPEd, 29. Anais... Rio de Janeiro, 2006.

LUCK, H. Pedagogia interdisciplinar: fundamentos teórico - metodológicos. Petrópolis:Vozes, 1999.

MADLUNG, A.et al. A Study Assessing the Potential of Negative Effects in Interdisciplinary Math-Biology Instruction. CBE-Life Sciences Education. v.10, p. 43-54, 2011. 
MORAN, J. Interdisciplinarity. 2 ed. New York: Routledge, 2010.

MORIN, E. Os sete saberes necessários à educação do futuro. 3. ed. São Paulo: Cortez; Brasília: UNESCO, 2001.

MORIN, E. A religação dos saberes: O desafio do séc. XXI. Rio de Janeiro: Beltrand Brasil, 2002.

MORIN, E. A Cabeça bem-feita. Rio de Janeiro: Bertrand Brasil, 2010.

PAVIANI, J. Disciplinaridade e interdisciplinaridade. 2003. Disponível em:

http://bdjur.stj.jus.br/dspace/handle/2011/25135 Último acesso: 26 jun. 2013.

POMBO, O. Interdisciplinaridade e integração de saberes. Liinc em revista. v.1, n.1, p. 3-15, 2005.

RAYNAUT, C. Meio ambiente e desenvolvimento: construindo um novo campo do saber a partir da perspectiva interdisciplinar. Desenvolvimento e Meio Ambiente, n. 10, p. 21-32, 2004.

ROBEVA, R.; LAUBENBACHER, R. Mathematical biology education:beyond calculus. Science. v. 325, p. 542-543, 2009.

SANTOS, M. L.; CALDEIRA, A.M.A. Interdisciplinaridade no ensino médio: a construção de um projeto coletivo por professores . In: ARAUJO, E.S.N.N.; CALUZI, J.J.; CALDEIRA, A.M.A. (Org.). Práticas integradas para o ensino de biologia. São Paulo: Escrituras, 2008. p.189-203

SEIPEL, M. Interdisciplinarity: an introduction, 2007. Disponível em:

http://www.uta.edu/faculty/repko/INTS_2301/SEIPEL.pdf . Acesso em: 26 jun. 2013.

SILVA, W. R. Construção da interdisciplinaridade no espaço complexo de ensino e pesquisa. Cadernos de pesquisa. v.41, n.143, p. 582-605, 2011.

THIESEN, J.S. A interdisciplinaridade como um movimento articulador no processo ensino-aprendizagem.

Revista Brasileira de Educação (online). v.13. n. 39, 2008. 
